\title{
NOTES ON TRANSLITERATION
}

I have used the IJMES system of transliteration (based on the modified Encyclopedia of Islam system of transliteration), although with a few modifications. While I have included macrons, 'ayns, and hamzas, I have not included dots. I have applied this transliteration not only to technical terms but also to names of political parties, titles of books, and personal names and place names when the English names are not well known. I have used the English version for names and places that are well known in English, such as Nasser, Sadat, and Shenouda. The only concession I make to Egyptian pronunciation of these names is the use of the " $\mathrm{g}$ " instead of " $\mathrm{j}$."

I have cited the source in the language in which I consulted that source, which means that I have cited Arabic sources in transliterated Arabic and I have cited translated sources that I consulted in English.

Readers might notice inconsistency in the transliteration of names in the footnotes. I consult a range of Arabic and English texts. In the footnotes, I have used the spelling of the name as it is found in the original source. In the case of Arabic texts, I have transliterated the name according to the system stated above. In the case of English texts, I have kept the transliteration that was used by the translator of the document. 

The Challenge of Political Islam 
